\title{
sone \\ Optimized Zirconia 3D Printing Using Digital Light Processing with Continuous Film Supply and a Recyclable Slurry System
}

\author{
Waqas Ahmed Sarwar ${ }^{1}$, Jin-Ho Kang ${ }^{2}$, and Hyung-In Yoon 1,* \\ ${ }^{1}$ Department of Prosthodontics, School of Dentistry and Dental Research Institute, Seoul National University, \\ Seoul, Korea; engr.raowaqas@gmail.com (W.A.S.); drhiy226@snu.ac.kr (H.-I.Y.) \\ 2 Deparment of Prosthodontics, School of Dentistry, Chonnam National University, Gwangju, Korea; \\ jhk.bme1002@gmail.com (J.-H.K.)

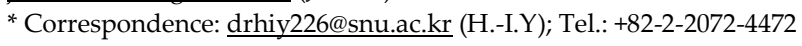

\begin{abstract}
Stereolithography (SL) can fabricate complex ceramic parts layer by layer using computer-aided design (CAD) models. The traditional SL system utilizes a vat, filled with ceramic slurry with high solid content, which for ceramics contributes to several limitations and operational difficulties, and further renders it non-recyclable mainly due to the presence of printed residue and high viscosity. In this study, we utilized a continuous film supply (CFS) system integrated with a tape-casting type digital light processing (DLP) printer to fabricate zirconia prototypes using with a solid content of 45 volume percent (vol.\%). Various printing and post-processing parameters were studied for optimization. to achieve a relative density of $99.02 \pm 0.08 \%$ with a microhardness of $12.59 \pm 0.47 \mathrm{GPa}$. The effectiveness of slurry reusability was also demonstrated by printing with recycled slurry to produce consistent relative density values in the range of $98.86 \pm 0.02 \%$ to 98.94 $\pm 0.03 \%$. This method provides new opportunities through material recycling and fabrication of dense complex ceramic product, reducing the consumption of the material.
\end{abstract}

Keywords: zirconia; digital light processing; continuous film supply; recyclable slurry

\section{Introduction}

Zirconia ceramics provide unique properties in the field of biomedical applications. They demonstrate a low affinity to bacterial plaque, limit inflammatory infiltration, and provide good soft-tissue integration. However, high-strength ceramics such as zirconia are relatively difficult to process into intricate and complex structures via subtractive machining, compared to metals and polymers. Additive manufacturing (AM) fabricates three-dimensional (3D) objects based on computer-aided design (CAD) models by depositing printable materials layer by layer. The AM process can produce a variety of complex and intricate geometrical shapes simultaneously in a single workflow, without wasting machining tools and production time. With all these benefits, additively manufactured ceramic products are available using various technologies such as binder jetting, powder bed fusion, material extrusion, and vat polymerization [1-3]. Stereolithography (SL) or digital light processing (DLP) projector-based vat polymerization has especially high production accuracy and excellent surface finish [4-8].

In vat-polymerization-based AM processes using ceramics, high solid loading is required to fabricate fully dense ceramic objects, causing the aggregation of ceramic particles in the slurry and resulting in high viscosity [9-11]. High viscosity produces challenges in maintaining accurate layer thickness and proper degassing. Although viscosity can be reduced by the use of diluents or temperature control, this is limited as diluents can cause adverse effects on the final density and produce high sintering shrinkage [12-17]. In addition, the recoating of the ceramic layer material during the printing recoating requires low 
viscosity of the slurry [18-21]. Homogenous temperature control of the whole vat area may help control the viscosity, though this is a challenging process [22].

Another major issue in vat polymerization with ceramics is the light scattering by ceramic particles, resulting in unwanted overgrowth of features that not only affects cure depth but also causes unexpected curing in bilateral directions [15,23-28]. Furthermore, the green printed state of ceramic material is fragile and lacking in strength to absorb the stresses involved in printing, making it susceptible to breakage during printing [29]. The presence of detached cured layers or partially failed samples in the vat poses hindrances for further printing, making the whole slurry potentially non-reusable. Overall, vat polymerization faces many challenges in the slurry dispensing system, which cannot accommodate higher viscosity without wasting slurry and processing time [30]. As an alternative method to vat polymerization, tape-casting-based additive manufacturing $[25,22,29]$ can be utilized to build up ceramic materials layer by layer. It uses a casting head that acts as both a slurry reservoir and a material dispensing system. It usually comprises a single doctor blade that shears the slurry into thin film onto the tape passing below the blades, providing a continuous film with uniform thickness [29]. It can also accommodate relatively higher-viscosity ceramics [29].

The purpose of this study was to produce high-density zirconia prototypes using a tape-casting type DLP printer with continuous film supply by optimization of processing parameters and to evaluate the recycling efficiency of the system. The zirconia ceramic slurry used in this AM was characterized and processed for the complete printing workflow. The viscosity, film thickness, slurry recycling efficiency, thermogravimetry, shrinkage rate, density, and microhardness were assessed to evaluate the performance of the printing system.

\section{Materials and Methods}

\subsection{Printer Design and Processing}

A modified version of a Onestage 6500 (Illuminaid Inc., Seoul, Korea) printer with the DLP projector was utilized for this research. The printer provides a continuous film of slurry to be printed as layers and is referred to as the 'continuous film supply (CFS) system' throughout this study. The schematic design for this printing machine is shown in Figure 1. It mainly consists of a transparent hydrophobic tape conveyor coated with silicone material, which moves from one roller to the other, passing through the casting head with dual doctor blades, a build platform, and a recycling blade. The film recoating thickness is controlled by physically controlling the double doctor blades and rolling speed. The projector installed for DLP has an LED light source with a maximum irradiance of $5.19 \mathrm{~mW} / \mathrm{cm}^{2}$ at a peak wavelength of $405 \mathrm{~nm}$.

The system worked in sequences running successively, one after another. The first sequence initiated the rollers to move the tape for a set distance with controlled speed, such that the slurry-recoated film arrived just under the build platform. The second sequence moved the build stage down to a set distance with controlled speed and decelerated close to its destination on the glass plate. The third sequence controlled the curing times for each designated set of layers of the whole process. The fourth sequence moved the platform up and the glass plate down, and finally, the manufacturing process repeated from the first sequence again. After hardening the selective area of the layer on the platform, the unused slurry was left on the tape. The unused slurry was peeled off from the tape using the recycling blade, where slurry flowed downward into the recycled slurry collector after passing through a mesh size of $100 \mu \mathrm{m}$ to remove any agglomerations produced during printing, such as detached layers or damaged samples. 


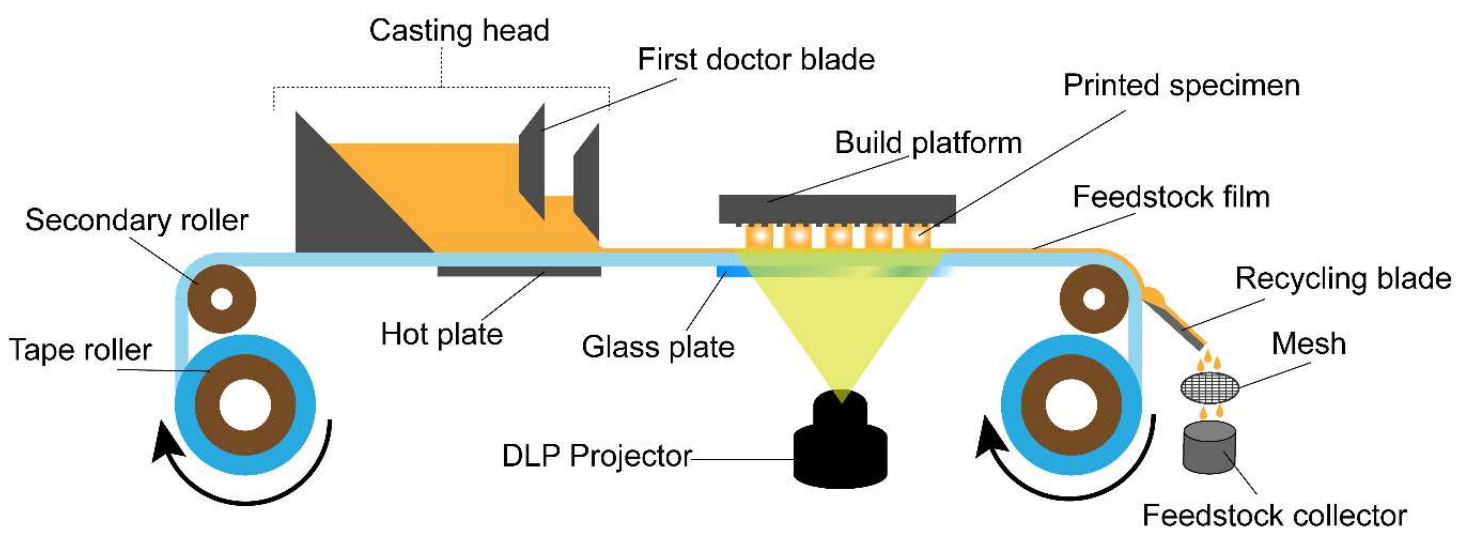

Figure 1. Schematic of the continuous film supply system with digital light processing during the three-dimensional printing process.

\subsection{Slurry Preparation}

A solvent-free photocurable ceramic suspension was formulated, containing highpurity ceramic powder dispersed in organic resin composed of two multifunctional acrylate monomers, two photoinitiators, and some processing additives. A $3 \mathrm{~mol} \%$ yttria-stabilized zirconia powder (TZ-3YS-E, Tosoh Corp) with an average particle size of $90 \mathrm{~nm}$ was used for this slurry. The zirconia ceramic powder was coated with the dispersant by ball milling in ethanol for $5 \mathrm{~h}$ and then dried in a vacuum oven at $30{ }^{\circ} \mathrm{C}$. A nonvolatile hydroxy-functional ester-based dispersant was chosen for the zirconia ceramic suspension, based on the surface chemistry of the ceramic powder and resin. For this research, a ceramic suspension with a solid loading of $45 \mathrm{vol} . \%$ was prepared to balance the required density and printable viscosity. A suspension with a solid loading of $44.65 \mathrm{vol} . \%$ was chosen for the recycling experiment to ease the filtration and recycling process. The prepared ceramic suspension (slurry) was further homogenized before printing with a planetary centrifugal mixer (Thinky Japan, ARE-310). The degassing process was then conducted at $-0.1 \mathrm{MPa}$ vacuum for $5 \mathrm{~min}$. The process of homogenization and degassing was also carried out for the recycled slurry.

\subsection{Specimen $3 D$ Printing}

The $3 \mathrm{D}$ printing of each specimen was performed according to the sequence mentioned above. The layer thickness was kept at $50 \mu \mathrm{m}$ for this research. Exposure energy of $20.76 \mathrm{~mJ} / \mathrm{cm}^{2}$ was applied to print each layer except for the first five layers, where 62.28 $\mathrm{mJ} / \mathrm{cm}^{2}$ was applied [31,32]. Other parameters used are mentioned in Table 1 . The wait time mentioned in the table refers to the time the build platform spent on the slurry film just before and after curing without changing its position. A standard tessellation language (STL) file format was used as a CAD model (Figure 2) with specimen dimensions of $7 \times 7 \times 4 \mathrm{~mm}$ scaled linearly in all dimensions considering compensation for the overgrowth percentage and sintering shrinkage.

Table 1. Several parameters used for printing.

\begin{tabular}{cc}
\hline Parameter & Value \\
\hline Wait time before curing & $12 \mathrm{~s}$ \\
Wait time after curing & $5 \mathrm{~s}$ \\
Tape speed & $8 \mathrm{~mm} / \mathrm{s}$ \\
Build platform speed (z-direction) & $1 \mathrm{~mm} / \mathrm{s}$ \\
Height of first blade & $1 \mathrm{~mm}$ \\
Height of second blade & $0.2 \mathrm{~mm}$ \\
\hline
\end{tabular}




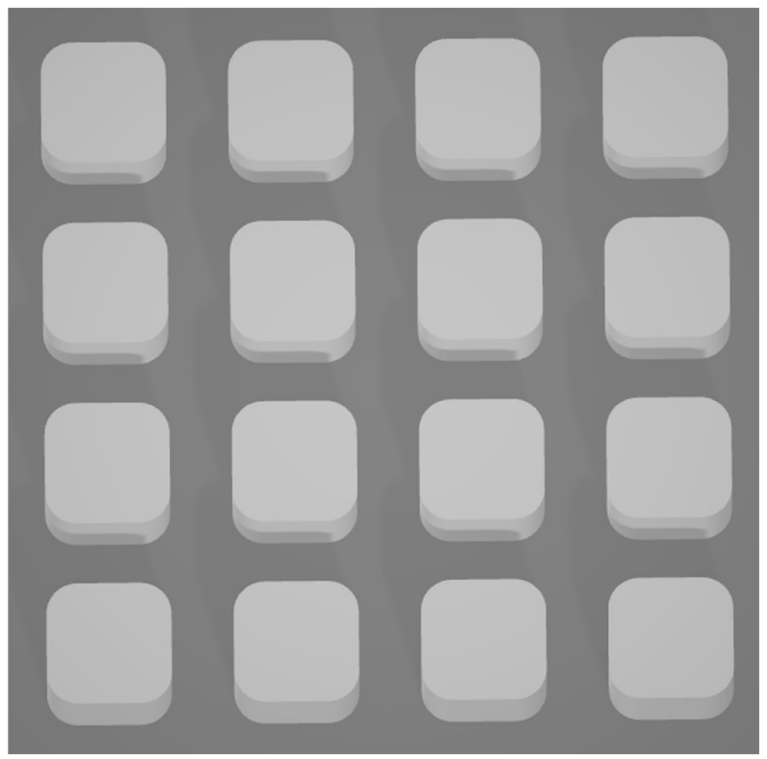

Figure 2. A standard tessellation language file image for the standard specimens to be printed.

\subsection{Post-Processing}

All the printed specimens were cleaned using isopropanol through a handheld atomizing spray. The debinding was performed using an atmosphere type 1 furnace (PT17EF022, PyroTech) in an argon atmosphere with a heating rate of $10^{\circ} \mathrm{C} / \mathrm{h}$ till $600{ }^{\circ} \mathrm{C}$ with a dwell time of $2 \mathrm{~h}$. A stairway approach to $600^{\circ} \mathrm{C}$ was used with several holding temperatures following derivative thermogravimetry analysis data. The sintering process was conducted in air at $1550{ }^{\circ} \mathrm{C}$ for $2 \mathrm{~h}$ with a heating rate of $2.5^{\circ} \mathrm{C} / \mathrm{h}$, shown in Figure 3 using the Super Kanthal furnace (AJ-SKB6, Ajeon). The weight percent values of the solid loading of specimens printed using the original ceramic slurry and recycled slurry were measured from the weight difference of the specimens after debinding and sintering.

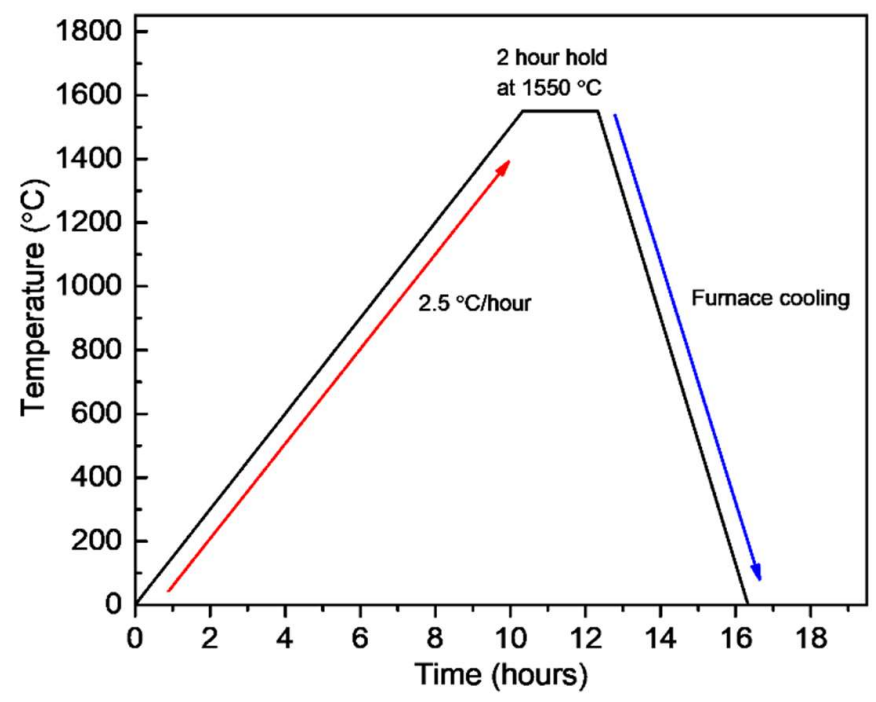

Figure 3. Sintering schedule followed in air atmosphere post debinding process.

\subsection{Viscosity Analysis}

The viscosity was measured for $2 \mathrm{~mL}$ of the ceramic slurry after degassing using a rotational rheometer (TA Instruments, ARES-G2) at $30^{\circ} \mathrm{C}, 40^{\circ} \mathrm{C}, 50{ }^{\circ} \mathrm{C}$, and $60^{\circ} \mathrm{C}$. 


\subsection{Film Thickness Analysis of Slurry}

The film thickness was measured using a micrometer (293-240-30, Mitutoyo, Kawasaki City, Japan) with an accuracy of $\pm 1 \mu \mathrm{m}$. The whole film above projector was hardened and an average value was taken after taking measurements across the width. Measurement was repeated 5 times to calculate standard deviation and maintain a consistent slurry amount behind the blade.

\subsection{Thermogravimetric Analysis}

Simultaneous thermogravimetric-derivative thermogravimetry analysis (TG-DTG) was conducted using an analyzer device (SDT-Q600, TA-instrument) on a printed cubic specimen with the size of $3 \times 3 \times 3 \mathrm{~mm}$, in argon atmosphere, and with a $1^{\circ} \mathrm{C} / \mathrm{min}$ temperature gradient from room temperature to $600{ }^{\circ} \mathrm{C}$.

\subsection{Density Analysis}

The density of the printed specimen was characterized via the Archimedean principle using 10 replicates and an analytical balance (Adam Equipment, SAB 125i) with readability of $10 \mu \mathrm{g}$. For recycled slurry, five replicates were used due to the limited amount of recycled slurry.

\subsection{Microhardness Testing}

The microhardness test value was measured by determining the Vickers hardness (Shimadzu, HMV-2) on mirror-polished cross-sections of specimens according to ASTM C1327-15. A loading force of $9.81 \mathrm{~N}$ for $10 \mathrm{~s}$ was applied, and the diagonals were measured through a $\times 40$ objective lens. A total of 10 specimens were tested with at least 5 indents each, and the average value for those indents was considered as the final hardness value of each specimen.

\subsection{Microstructure Analysis}

The microstructure analysis was performed through a field-emission scanning electron microscope (AURIGA, Carl Zeiss) on platinum-coated specimens with a coating thickness of $5 \mathrm{~nm}$. The analysis was carried out on the fine-polished cross-sections of both as-printed specimens and sintered specimens after thermal etching at $1450{ }^{\circ} \mathrm{C}$ for $40 \mathrm{~min}$. The grain size was measured for 5 sintered samples, printed in separate batches, by linear intercept method with the conversion factor of 1.56 [33].

\section{Results and Discussion}

\subsection{Viscosity Analysis}

Slurry with 45 vol.\% solid loading of zirconia coated with dispersant was tested at four different temperatures; however, it was found that the slurry started to thermally cure at temperatures higher than $60^{\circ} \mathrm{C}$. At around $60^{\circ} \mathrm{C}$, the slurry started to show signs of thermal curing and formed agglomerates which started to collect in the recycling mesh. The viscosity seemed to decrease exponentially with rising temperature (Figure 4a). Viscosity decreased by a factor of 4 from $57 \mathrm{~Pa}$.s at $30^{\circ} \mathrm{C}$ to $13 \mathrm{~Pa}$.s at $50{ }^{\circ} \mathrm{C}$. The effect of the dispersant also played a role in this decrease in viscosity at higher temperatures, as the dispersant is most effective at temperatures higher than $30^{\circ} \mathrm{C}$. A working temperature of $50^{\circ} \mathrm{C}$ was chosen considering the lowest available viscosity without the possibility of thermal curing of the slurry. The doctor blade requires a suitable viscosity range to make a homogenous film. To control and increase the printable viscosity range, temperature control and a proper dispersant at an optimized amount are essential [22,34]. The casting head, which acts as a slurry reservoir, has a hot plate below it to control temperature. Furthermore, a diluent can also be used to drastically reduce the viscosity; however, to 
avoid higher sintering shrinkage and to retain sufficient viscosity for the doctor blade, a diluent was not used.

At $50{ }^{\circ} \mathrm{C}$, the viscosity was also tested with varying shear rates (Figure $4 \mathrm{~b}$ ). The viscosity decreased from $12.26 \times 103 \mathrm{mPa}$.s at $3 \mathrm{~s}^{-1}$ to $96.95 \mathrm{mPa}$.s at $160 \mathrm{~s}^{-1}$. The flow curve was consistent with non-Newtonian flow behavior and showed pseudoplastic behavior. Considering that the tape velocity under the casting head was $8 \mathrm{~mm} / \mathrm{s}$, the viscosity was found to be in a suitable range for the doctor blades to sufficiently coat slurry film with a uniform thickness.
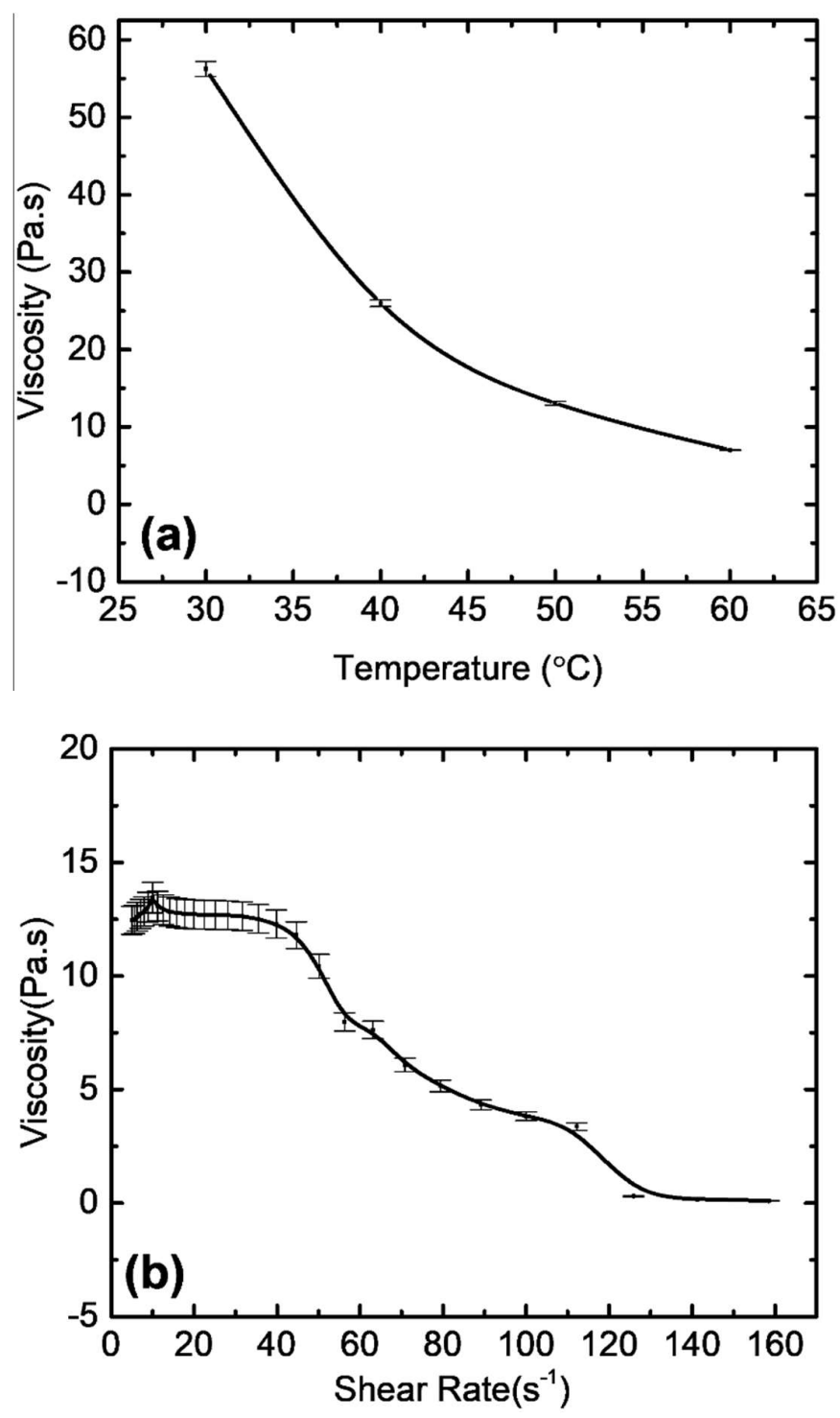

Figure 4. (a) Change in viscosity with the temperature at a $10 \mathrm{~s}^{-1}$ shear rate; (b) Effect of shear rate on the viscosity of zirconia slurry at $50{ }^{\circ} \mathrm{C}$. 


\subsection{Film Thickness of Slurry}

Figure 5 shows the effect of the slurry amount in the casting head behind the blades on the coated film thickness. It shows two trends, with the first trend (dotted) starting with the slurry reservoir filled $100 \%$ with slurry and the second trend (solid) starting from $10 \%$ slurry. The dotted line depicts the natural process of recoating during printing with the slurry amount reducing as printing continues. The solid line depicts a trend when, at any point during printing, the reservoir is filled again with fresh or recycled slurry. Considering the dotted line, the film thickness stays consistent with a mean difference of $5 \pm 1$ $\mu \mathrm{m}$ from $100 \%(149 \pm 2 \mu \mathrm{m})$ to $25 \%(154 \pm 2 \mu \mathrm{m})$ slurry amount. For the solid line, the mean film thickness was between $86 \pm 3 \mu \mathrm{m}$ and $90 \pm 3 \mu \mathrm{m}$, when the slurry amount varies from $20 \%$ to $100 \%$, respectively. If a partial area is observed in the case of refill, the mean difference in film thickness was $4 \pm 2 \mu \mathrm{m}$.

The film thickness depends on the viscosity, hydrodynamic pressure, tape speed, width of the blades, and density of the slurry $[25,35,36]$. Viscosity plays an important role and can diversely change the flow pattern of slurry; however, with a consistent viscosity, the flow pattern slightly changes with Newtonian and non-Newtonian fluids [37]. In this study, the CFS utilized a dual-blade casting head which in case of variation in slurry amount behind the first blade causes a minor change in film thickness if sufficient velocity of the tape was maintained [38,39]. However, in the case of a non-steady state, the effect of slurry addition to complete the printing process (recycling) on the film thickness is also important. This addition of slurry at any time causes a sudden change in hydrodynamic pressure behind the blades, which can eventually affect film thickness. The effect of refilling the casting head had minute changes on film thickness unless it fell below a certain slurry height, which, in our case, was determined to be less than $25 \%(10 \mathrm{~mm})$ of total capacity. Layer thickness was controlled by the position of the build platform before curing. The build platform maintained its height for the programmed layer thickness. Recoated film was always fabricated 50-80 $\mu \mathrm{m}$ higher than the programmed layer thickness for compensation, which was then pushed out by compression by the build plate to cure exact layer thickness. Considering this alternative film recoating system of the doctor blades, the accurate layer thickness can be maintained with highly viscous slurry conditions, even when the slurry was below $10 \%$ capacity of the casting head, by the use of compensation. The loss of excessive slurry on the film was recovered by recycling.

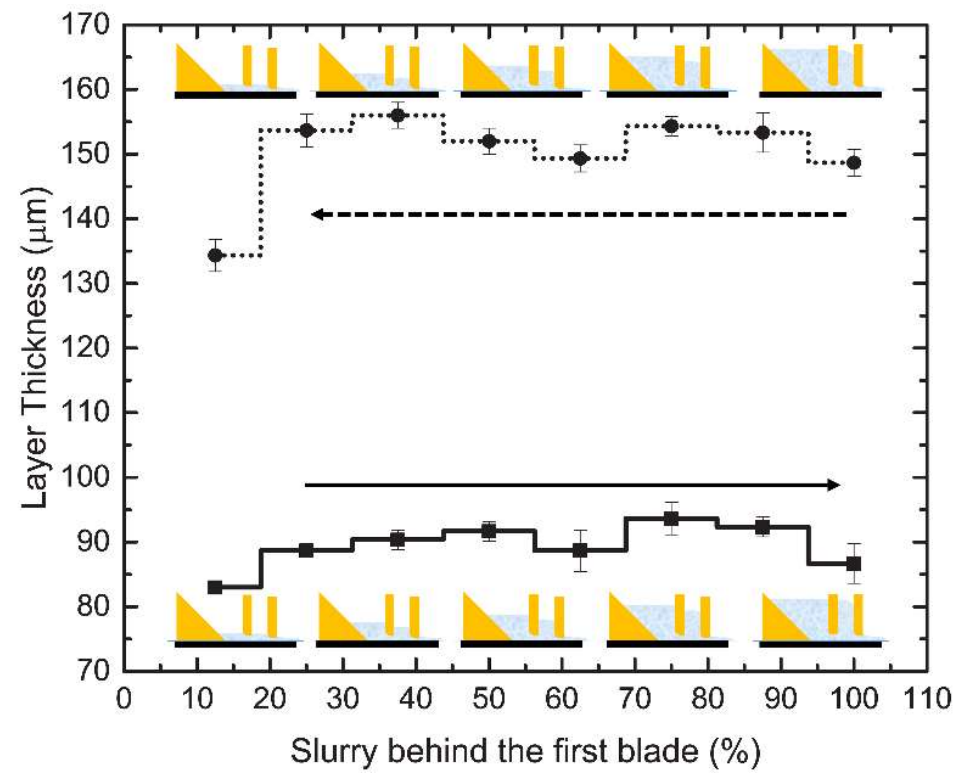

Figure 5. Film thickness measurement on the tape versus slurry level behind the first doctor blade. First with ascending level (solid line); second with descending level (dotted line). 


\subsection{Thermogravimetric Analysis}

Post-processing after cleaning and drying started with binder burnout, which was carried out separately from sintering to check the effectiveness of binder burnout and diagnose the initiation of possible thermal cracks. The DW (derivative of weight) curve shown in Figure 6 exhibits a sequence of peaks that indicate the presence of many phase changes during thermal degradation. Even though there are three distinctive peaks between $300{ }^{\circ} \mathrm{C}$ and $500{ }^{\circ} \mathrm{C}$, their lower portions overlap with each other, which could, in some cases, hide smaller peaks in the overlapped regions. This makes the debinding process in this temperature zone heat sensitive, and it requires a comparatively lower heating rate. A heating rate of $10^{\circ} \mathrm{C} / \mathrm{h}$ in argon was utilized considering the overlapping peaks in the DW curve to eliminate thermal cracks, as air atmosphere was found to cause thermal cracks after debinding even at a slower heating rate of $5^{\circ} \mathrm{C} / \mathrm{h}$.

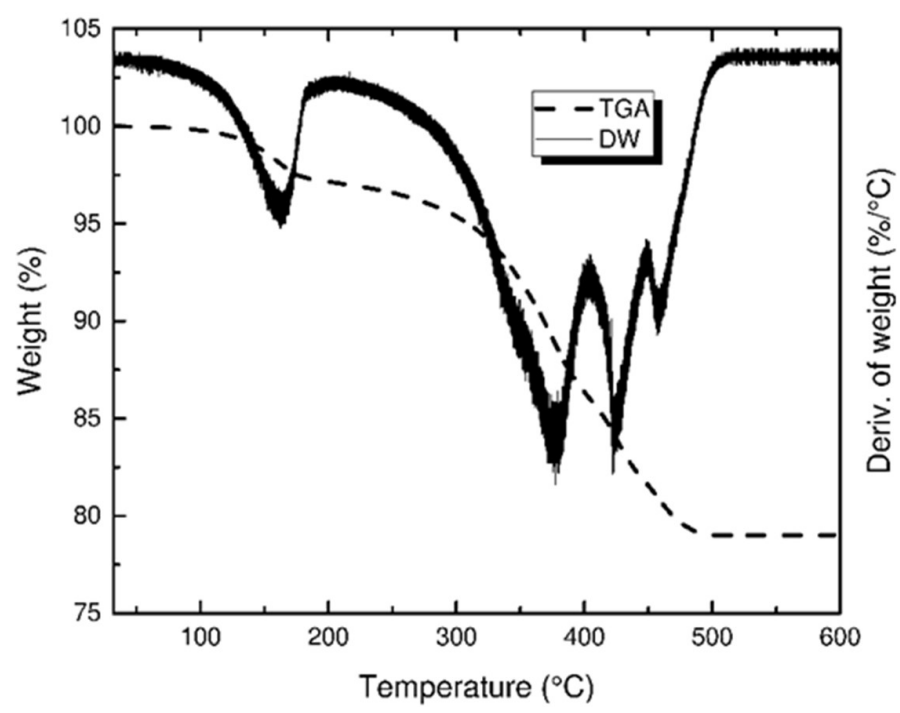

Figure 6. Thermogravimetric analysis representing both weight change percent and the rate of change of weight vs temperature in an argon atmosphere.

Oxidative degradation produced mainly gaseous products which, under hindered diffusion, can create microcracks and blisters due to pressure build-up of gas inside the sample. In the case of thermal degradation, polymer chains break down by chain scission with by-products including carbon black, carbon monoxide, ammonia aliphatic amines, ketones, nitriles, and hydrogen cyanide [40]. Thermal degradation involves the removal of functional groups one after the other to leave behind only carbon black. Thermal degradation is a much slower process and can be considered more sensitive as compared to oxidative degradation when compared to crack formation during post-processes. To avoid thermal stresses and cracks in sintered products, debinding was performed in an argon environment.

\subsection{Densification}

After cleaning, drying was performed at room temperature, and no observable drying shrinkage was detected. In this study, the $45 \mathrm{vol} . \%$ was the optimum solid loading in an argon atmosphere to achieve relative densification of $99.02 \pm 0.08 \%\left(5.99 \pm 0.01 \mathrm{~g} / \mathrm{cm}^{3}\right)$ for zirconia. Linear shrinkage is shown in Table 2, which indicates homogenous sintering with shape retention and lack of deformation during post-processing. Uniform sintering shrinkage in all dimensions is essential for any application, especially to produce an accurate final product. The shrinkage rate of $20-25 \%$ was within the normal limits for traditional CAD/CAM pre-sintered zirconia blocks [41,42]. 
Table 2. Sintering shrinkage in all directions.

\begin{tabular}{ccc}
\hline X-Direction (\%) & Y-Direction (\%) & Z-Direction (\%) \\
\hline $22.59 \pm 0.19$ & $22.48 \pm 0.15$ & $22.56 \pm 0.11$ \\
\hline
\end{tabular}

\subsection{Slurry Recycling Efficiency}

All the residual slurry remaining on the tape was recycled after filtration and could be recycled again and used to refill the casting head after degassing for continuous printing. The characterization of samples printed using recycled slurry is given in Table 3 . The results showed that there was a change in solid loading of 0.12 weight percent for the first recycling instance and 0.26 weight percent for the second recycling instance. Changes in solid loading for recycled slurry can be explained by considering scattering agglomeration, which is the curing of slurry present near the exposed light area by light scattered by ceramic powder $[25,43,44]$. However, such a minute change in weight percent in a highsolid-load slurry was negligible. This was evident in the relative density of samples prepared only by using recycled slurry unmixed with fresh slurry, as there was only a slight change in density, making printing possible even after two instances of recycling. In practice, recycled slurry gets mixed with the fresh slurry already present in the casting head, which can reduce solid loading changes further.

Table 3. Change in properties with recycling.

\begin{tabular}{ccccc}
\hline & First Use & Recycled Once & Recycled Twice & Recycled Thrice \\
\hline Weight percent (\%) & $81.32 \pm 0.03$ & $81.44 \pm 0.04$ & $81.58 \pm 0.06$ & $81.61 \pm 0.02$ \\
\hline Relative Density (\%) & $98.89 \pm 0.03$ & $98.86 \pm 0.02$ & $98.94 \pm 0.03$ & $98.91 \pm 0.03$ \\
\hline
\end{tabular}

\subsection{Microhardness Test}

Sintered specimens showed an average microhardness of $12.59 \pm 0.47 \mathrm{GPa}$. As observed from Figure 7, the shape of the indent was symmetrical, the cracks produced at the corners of the square pyramid were linear, and it was well within the range of acceptable indentation by ASTM. Only indents producing Palmqvist cracks were measured for diagonals, and unsymmetrical indents were ignored during the measurement. The indentation seemed to include microporosity, as seen inside the pyramid; however, the porosity was not large enough to deform the indentation. A microhardness over $12 \mathrm{GPa}$ at 45 vol.\% solid loading was well within the reported value produced by additive manufacturing and conventional subtractive machining of zirconia plates $[45,46]$.

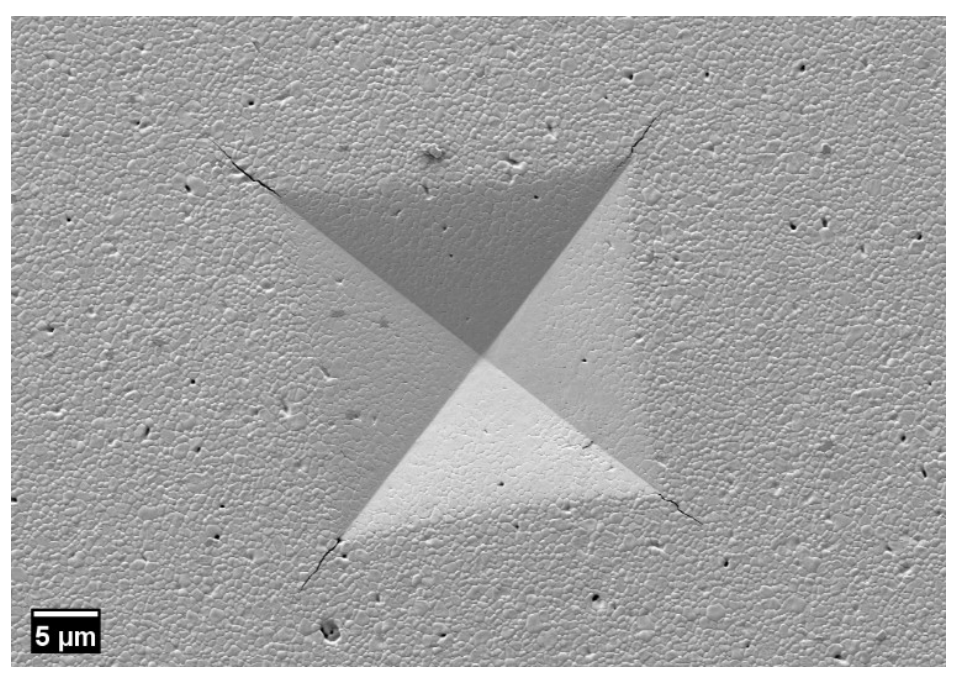

Figure 7. Indent at $1000 \times$ magnification for reference. 


\subsection{Microstructure Analysis}

The sintered cross-section did not show any signs of boundaries between layers, which were visible before debinding, as seen in Figure 8. This disappearance of layer boundaries after sintering is not common among traditional vat polymerization printed parts. The disappearance of layer boundaries after sintering and attaining a relative density of more than $99 \%$ at 45 vol.\% showed that tape casting produced compact as-printed objects. The DLP with CFS system showed promise in producing dense structures. The as-printed specimen is shown in Figure 9a as an example of printability. Furthermore, the microstructure at 30,000× magnification showed a mean grain size of $644 \pm 20 \mathrm{~nm}$ and was densely packed, as evident in Figure 9b. However, further refinement of the grain size could be achieved by increasing solid loading and decreasing the sintering temperature.
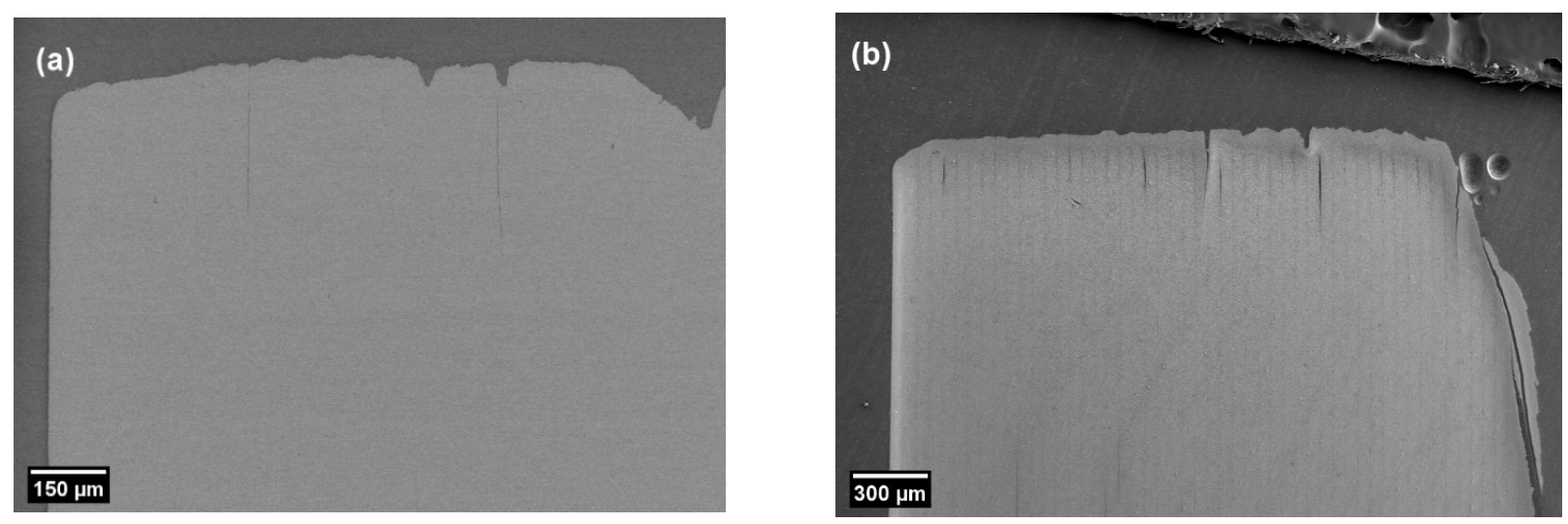

Figure 8. (a) Cross-section of sintered specimen at 200× (back-scattered electron mode) to observe any layer boundaries; (b) cross-section of as-printed specimen at $100 \times$ to observe distinctive layer boundaries.

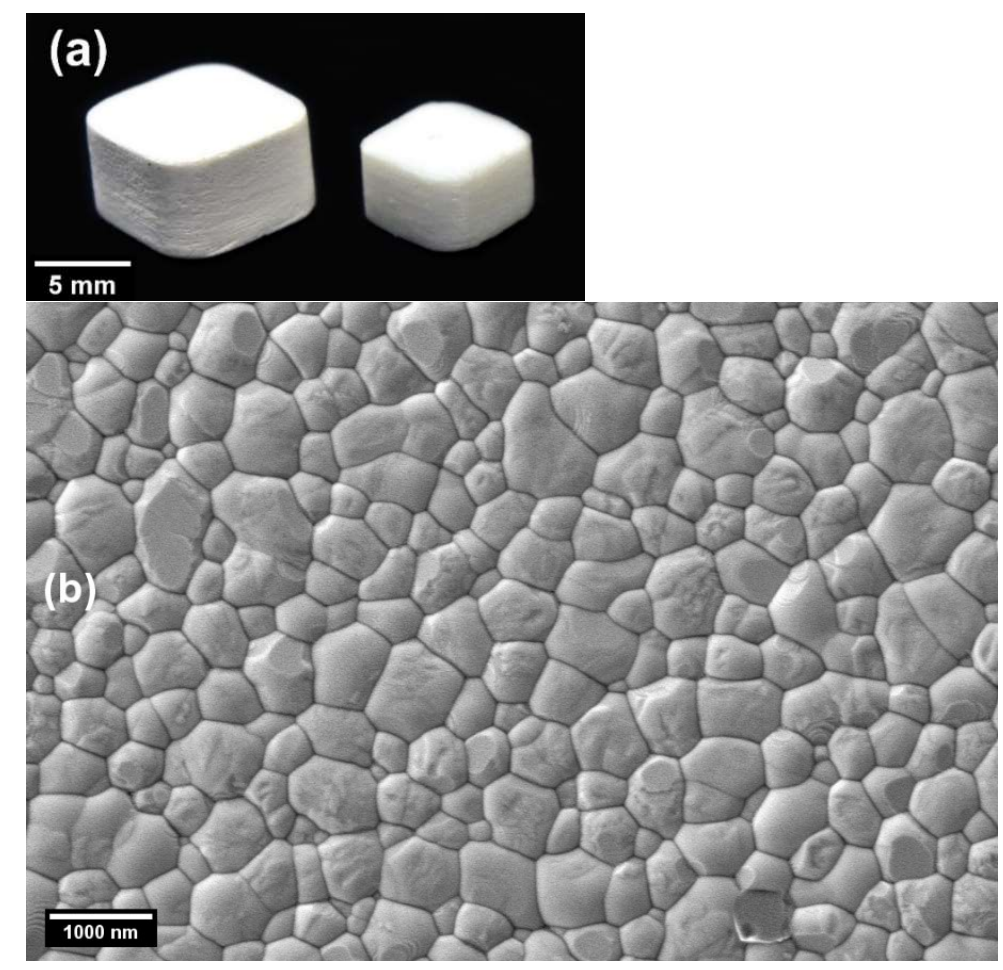

Figure 9. (a) As-printed and sintered samples for reference; (b) Microstructure of the polished cross-section of $45 \mathrm{vol}$ \% solid loaded zirconia at $30,000 \times$. 


\section{Conclusions}

Based on this study, the tape casting DLP printing with CFS was a capable alternative to vat polymerization to print dense zirconia prototypes using high-viscosity slurry. An appropriate dispersant and working temperature were necessary to achieve printable viscosity. Consistency of film thickness on tape throughout the whole printing process was imperative for the DLP with CFS. The dual doctor blades were found to produce film thickness well above set layer thickness overall. Using the DLP with CFS, a 45 vol.\% solid loaded 3Y-TZP slurry was used to fabricate ceramic products of homogenous microstructure with the relative density of $99.02 \pm 0.08 \%$ and the mean grain size of $644 \pm 20 \mathrm{~nm}$, after post-processing. The microhardness value of the ceramic product was $12.59 \pm 0.47 \mathrm{GPa}$. Furthermore, the DLP with CFS can effectively recycle and reuse slurry, providing a consistent density for at least two instances of recycling, making it a competitive alternative to conventional processing techniques for the fabrication of dense ceramic products.

Author Contributions: Conceptualization, H.-I.Y.; methodology, H.-I.Y., W.A.S. and J.-H.K.; formal analysis, W.A.S.; writing - original draft preparation, W.A.S.; writing-review and editing, H.-I.Y., W.A.S. and J.-H.K.; supervision, H.-I.Y.; funding acquisition, H.-I.Y. All authors have read and agreed to the published version of the manuscript.

Funding: This work was supported by Creative-Pioneering Researchers Program through Seoul National University (SNU, 860-20200093)

Conflicts of Interest: The authors declare no conflict of interest.

\section{References}

1. Jang, K.J.; Kang, J.H.; Fisher, J.G.; Park, S.W. Effect of the volume fraction of zirconia suspensions on the microstructure and physical properties of products produced by additive manufacturing. Dent. Mater. 2019, 35, e97-e106, doi:10.1016/j.dental.2019.02.001.

2. Kang, J.H.; Kaneda, J.; Jang, J.G.; Sakthiabirami, K.; Lui, E.; Kim, C.; Wang, A.; Park, S.W.; Yang, Y.P. The Influence of Electron Beam Sterilization on In Vivo Degradation of beta-TCP/PCL of Different Composite Ratios for Bone Tissue Engineering. Micromachines 2020, 11, 273, doi:10.3390/mi11030273.

3. Kang, J.-H.; Jang, K.-J.; Sakthiabirami, K.; Oh, G.-J.; Jang, J.-G.; Park, C.; Lim, H.-P.; Yun, K.-D.; Park, S.-W. Mechanical properties and optical evaluation of scaffolds produced from 45S5 bioactive glass suspensions via stereolithography. Ceram. Int. 2020, 46, 2481-2488, doi:10.1016/j.ceramint.2019.09.242.

4. Ruiz-Morales, J.C.; Tarancón, A.; Canales-Vázquez, J.; Méndez-Ramos, J.; Hernández-Afonso, L.; Acosta-Mora, P.; Marín Rueda, J.R.; Fernández-González, R. Three dimensional printing of components and functional devices for energy and environmental applications. Energy Environ. Sci. 2017, 10, 846-859, doi:10.1039/C6EE03526D.

5. Hernández, E.; Acosta-Mora, P.; Méndez-Ramos, J.; Borges, M.; Esparza, P.; Canales-Vázquez, J.; Núñez, P.; Ruiz-Morales, J.C. Prospective use of the 3D printing technology for the microstructural engineering of Solid Oxide Fuel Cell components. Comput. Aided Des. 2014, 53, 213-216, doi:10.3989/cyv.252014.

6. Tamayo-Domínguez, A.; González, J.M.F.; Sierra-Castañer, M. Stereolithography and Direct Metal Laser Sintering Applied to mm-Wave Antennas. In Proceedings of the 2020 International Symposium on Antennas and Propagation (ISAP), 25-28 Jan. 2021, 2021; pp. 273-274.

7. Wang, W.; Sun, J. Dimensional accuracy and clinical adaptation of ceramic crowns fabricated with the stereolithography technique. The Journal of Prosthetic Dentistry 2021, 125, 657-663, doi:https://doi.org/10.1016/j.prosdent.2020.02.032.

8. Xing, H.; Zou, B.; Liu, X.; Wang, X.; Huang, C.; Hu, Y. Fabrication strategy of complicated Al2O3-Si3N4 functionally graded materials by stereolithography 3D printing. Journal of the European Ceramic Society 2020, 40, 5797-5809, doi:https://doi.org/10.1016/j.jeurceramsoc.2020.05.022.

9. Zhang, K.; Meng, Q.; Cai, N.; Qu, Z.; He, R. Effects of solid loading on stereolithographic additive manufactured ZrO2 ceramic: A quantitative defect study by X-ray computed tomography. Ceramics International 2021, doi:https://doi.org/10.1016/j.ceramint.2021.05.149.

10. Hu, K.; Wei, Y.; Lu, Z.; Wan, L.; Li, P. Design of a Shaping System for Stereolithography with High Solid Loading Ceramic Suspensions. 3D Print. Addit. Manuf. 2018, 5, 311-318, doi:10.1089/3dp.2017.0065.

11. Zhang, K.; Xie, C.; Wang, G.; He, R.; Ding, G.; Wang, M.; Dai, D.; Fang, D. High solid loading, low viscosity photosensitive $\mathrm{A} 12 \mathrm{O} 3$ slurry for stereolithography based additive manufacturing. Ceram. Int. 2019, 45, 203-208, doi:10.1016/j.ceramint.2018.09.152.

12. Li, K.; Zhao, Z. The effect of the surfactants on the formulation of UV-curable SLA alumina suspension. Ceram. Int. 2017, 43, 4761-4767, doi:https://doi.org/10.1016/j.ceramint.2016.11.143. 
13. Wang, Z.; Huang, C.; Wang, J.; Zou, B. Development of a novel aqueous hydroxyapatite suspension for stereolithography applied to bone tissue engineering. Ceram. Int. 2019, 45, 3902-3909, doi:https://doi.org/10.1016/j.ceramint.2018.11.063.

14. Lee, Y.-H.; Lee, J.-B.; Maeng, W.-Y.; Koh, Y.-H.; Kim, H.-E. Photocurable ceramic slurry using solid camphor as novel diluent for conventional digital light processing (DLP) process. J. Eur. Ceram. Soc. 2019, 39, 4358-4365, doi:https://doi.org/10.1016/j.jeurceramsoc.2019.05.069.

15. Johansson, E.; Lidström, O.; Johansson, J.; Lyckfeldt, O.; Adolfsson, E. Influence of Resin Composition on the Defect Formation in Alumina Manufactured by Stereolithography. Materials 2017, 10, 138.

16. Melchels, F.P.W.; Feijen, J.; Grijpma, D.W. A poly(d,l-lactide) resin for the preparation of tissue engineering scaffolds by stereolithography. Biomaterials 2009, 30, 3801-3809, doi:10.1016/j.biomaterials.2009.03.055.

17. Jang, J.H.; Wang, S.; Pilgrim, S.M.; Schulze, W.A. Preparation and characterization of barium titanate suspensions for stereolithography. J. Am. Ceram. Soc. 2000, 83, 1804-1806.

18. Goswami, A.; Ankit, K.; Balashanmugam, N.; Umarji, A.M.; Madras, G. Optimization of rheological properties of photopolymerizable alumina suspensions for ceramic microstereolithography. Ceram. Int. 2014, 40, 3655-3665, doi:10.1016/j.ceramint.2013.09.059.

19. Janusziewicz, R.; Tumbleston, J.R.; Quintanilla, A.L.; Mecham, S.J.; DeSimone, J.M. Layerless fabrication with continuous liquid interface production. Proc. Natl. Acad. Sci. USA 2016, 113, 11703-11708, doi:10.1073/pnas.1605271113.

20. Li, X.; Wang, M.; Xing, L.; Chu, J.; Bao, Y. Experimental and Numerical Investigation on Surface Damage of Cold Rolled Sheet Caused by Inclusion Movement. Cham, 2020; pp. 239-247.

21. Wu, Z.; Liu, W.; Wu, H.; Huang, R.; He, R.; Jiang, Q.; Chen, Y.; Ji, X.; Tian, Z.; Wu, S. Research into the mechanical properties, sintering mechanism and microstructure evolution of Al2O3-ZrO2 composites fabricated by a stereolithography-based 3D printing method. Mater. Chem. Phys. 2018, 207, 1-10, doi:https://doi.org/10.1016/j.matchemphys.2017.12.021.

22. Hinczewski, C.; Corbel, S.; Chartier, T. Ceramic suspensions suitable for stereolithography. J. Eur. Ceram. Soc. 1998, 18, 583-590, doi:10.1016/S0955-2219(97)00186-6.

23. O'Masta, M.R.; Stonkevitch, E.; Porter, K.A.; Bui, P.P.; Eckel, Z.C.; Schaedler, T.A. Additive manufacturing of polymer-derived ceramic matrix composites. J. Am. Ceram. Soc. 2020, 103, 6712-6723, doi:https://doi.org/10.1111/jace.17275.

24. Jang, K.-J.; Kang, J.-H.; Fisher, J.G.; Park, S.-W. Effect of the volume fraction of zirconia suspensions on the microstructure and physical properties of products produced by additive manufacturing. Dent. Mater. 2019, 35, e97-e106, doi:https://doi.org/10.1016/j.dental.2019.02.001.

25. Alazzawi, M.K.; Beyoglu, B.; Haber, R.A. A study in a tape casting based stereolithography apparatus: Role of layer thickness and casting shear rate. Journal of Manufacturing Processes 2021, 64, 1196-1203, doi:https://doi.org/10.1016/j.jmapro.2021.02.040.

26. Halloran, J.W. Ceramic Stereolithography: Additive Manufacturing for Ceramics by Photopolymerization. Annu. Rev. Mater. Res. 2016, 46, 19-40, doi:10.1146/annurev-matsci-070115-031841.

27. Gentry, S.P.; Halloran, J.W. Depth and width of cured lines in photopolymerizable ceramic suspensions. J. Eur. Ceram. Soc. 2013, 33, 1981-1988.

28. Gentry, S.P.; Halloran, J.W. Light scattering in absorbing ceramic suspensions: Effect on the width and depth of photopolymerized features. J. Eur. Ceram. Soc. 2015, 35, 1895-1904.

29. Song, X.; Chen, Y.; Lee, T.W.; Wu, S.; Cheng, L. Ceramic fabrication using Mask-Image-Projection-based Stereolithography integrated with tape-casting. J. Manuf. Process. 2015, 20, 456-464, doi:10.1016/j.jmapro.2015.06.022.

30. Song, X. Slurry Based Stereolithography: A Solid Freeform Fabrication Method of Ceramics and Composites; University of Southern California: Los Angeles, CA, USA, 2016.

31. Mills, P.; Raymont, J. Ultraviolet (UV) measurement for formulators: Park I. RadTech Rep. 2009, $23,34$.

32. Conti, L.; Bienenstein, D.; Borlaf, M.; Graule, T. Effects of the Layer Height and Exposure Energy on the Lateral Resolution of Zirconia Parts Printed by Lithography-Based Additive Manufacturing. Materials 2020, 13, 1317.

33. Mendelson, M.I.; Average Grain Size in Polycrystalline Ceramics. J. Am. Ceram. Soc. 1969, 52, 443-446, doi:https://doi.org/10.1111/j.1151-2916.1969.tb11975.x.

34. Robert, G.O.; Timothy, N.P. Computational Rheology; Imperial College Press: London, UK, 2002.

35. Chou, Y.T.; Ko, Y.T.; Yan, M.F. Fluid flow model for ceramic tape casting. J. Am. Ceram. Soc. 1987, 70, C-280-C-282.

36. Huang, X.; Liu, C.; Gong, H. A viscoplastic flow modeling of ceramic tape casting. Mater. Manuf. Process. 1997, 12, $935-943$.

37. Wonisch, A.; Polfer, P.; Kraft, T.; Dellert, A.; Heunisch, A.; Roosen, A. A Comprehensive Simulation Scheme for Tape Casting: From Flow Behavior to Anisotropy Development. J. Am. Ceram. Soc. 2011, 94, 2053-2060, doi:10.1111/j.1551-2916.2010.04358.x.

38. Zhang, G.; Wang, Y.; Ma, J. Bingham plastic fluid flow model for ceramic tape casting. Mater. Sci. Eng. A 2002, 337, 274-280, doi:10.1016/S0921-5093(02)00043-6.

39. Jabbari, M.; Hattel, J. Bingham plastic fluid flow model in tape casting of ceramics using two doctor blades-Analytical approach. Mater. Sci. Technol. 2014, 30, 283-288, doi:10.1179/1743284713Y.0000000313.

40. Trunec, M.; Cihlar, J. Removal of thermoplastic binders from ceramic green bodies. Ceramics 1997, 41, 67-80.

41. Raigrodski, A.J. Contemporary all-ceramic fixed partial dentures: A review. Dent. Clin. N. Am. 2004, 48, 531-544, doi:10.1016/j.cden.2003.12.008.

42. Besimo, C.E.; Spielmann, H.P.; Rohner, H.P. Computer-assisted generation of all-ceramic crowns and fixed partial dentures. Int. J. Comput. Dent. 2001, 4, 243-262. 
43. Sun, C.; Zhang, X. The influences of the material properties on ceramic micro-stereolithography. Sens. Actuators A Phys. 2002, 101, 364-370, doi:10.1016/S0924-4247(02)00264-9.

44. Mitteramskogler, G.; Gmeiner, R.; Felzmann, R.; Gruber, S.; Hofstetter, C.; Stampfl, J.; Ebert, J.; Wachter, W.; Laubersheimer, J. Light curing strategies for lithography-based additive manufacturing of customized ceramics. Addit. Manuf. 2014, 1, 110-118.

45. Cottom, B.A.; Mayo, M.J. Fracture toughness of nanocrystalline $\mathrm{ZrO}_{2}-3 \mathrm{~mol} \% \mathrm{Y}_{2} \mathrm{O}_{3}$ determined by Vickers indentation. Scr. Mater. 1996, 34, 809-814, doi:10.1016/1359-6462(95)00587-0.

46. Ruiz, L.; Readey, M.J. Effect of Heat Treatment on Grain Size, Phase Assemblage, and Mechanical Properties of 3 mol\% Y-TZP. J. Am. Ceram. Soc. 1996, 79, 2331-2340, doi:10.1111/j.1151-2916.1996.tb08980.x. 